\title{
EMPIRICAL INSIGHTS ON UNDERSTANDING STAKEHOLDER INFLUENCE
}

\section{Dalia SUSNIENÉ1, Ojaras PURVINIS ${ }^{2}$}

\author{
${ }^{1}$ Department of Economics, Faculty of Management and Administration, Panevėžys Institute \\ of Kaunas University of Technology, Klaipèdos g. 1, LT-35209 Panevėžys, Lithuania \\ ${ }^{2}$ Department of Physical Sciences, Faculty of Technologies, Panevezzys Institute of Kaunas \\ University of Technology, Klaipèdos g. 1, LT-35209 Panevėzys, Lithuania \\ E-mails: 1dalia.susniene@ktu.lt (corresponding author);2ojaras.purvinis@ktu.lt
}

Received 22 September 2012; accepted 12 March 2013

\begin{abstract}
The paper deals with the stakeholder management especially giving focus on the organization's and stakeholder relationships issues. The purpose of the paper is to construct a new methodological approach by developing fuzzy logic model based on experts' knowledge for conceptual insights on possible solutions for measuring stakeholders' influence. The objective of the research includes identification of possible organizationstakeholder interactions considering stakeholders' influence according to such attributes/ factors as interest, power, benevolence, and reliability. The results reveal that fuzzy logic technique is a reliable and valid tool for modelling and visualizing knowledge about stakeholders' influence on the organization. Finally, the results were tested on the real business data concerning stakeholders' influence. A contribution of this paper is the application of fuzzy logic model to evaluate and/or predict stakeholders' influence to the issues the organization seeks to solve and to provide relevant information for the stakeholder relationships management.
\end{abstract}

Keywords: stakeholder management, influence, relationships, attributes, fuzzy logic, interactions.

JEL Classification: L21, M14, M10, M19.

\section{Introduction}

Nowadays a stakeholder orientated perspective of the organization is often discussed in academic literature and practice as it is a good tool for pursuing sustainability and social responsibility CSR). CSR comprises a number of corporate activities that focus on the welfare of stakeholder groups other than investors, such as charitable and community organizations, employees, suppliers, customers, and future generations (Sprinkle, Maines 2010; Duijvesteijn et al. 2014). There is a strong relationship among parties which are internal and external and each party requires reciprocal data sharing (West, Turner 2007) involving obligations towards stakeholders (Metaxas, Tsavdaridou 2010) and creative communication. This implies the need of stakeholder management in the organization 
as it is seen as nexus of the parties / stakeholders involved. The principal argument of stakeholder management is that organizations should be operated and managed in the interests of all their constituents who can affect or be affected by the achievement of the organization's objectives (Benson et al. 2011; Freeman 1984; Donaldson, Preston 1995). Stakeholder management captures various organization-stakeholder relationships where proponents and opponents discuss the issue. Proponents maintain that stakeholder management is strategically important, and organizations can benefit from proper management of their relationships with these important groups which lead to an increase in the overall total good created by the enterprise (Singer 2013; Benson et al. 2011; Bhattacharya et al. 2009; Fung 2009). But the key argument used by the opponents is the need of using organization's limited recourses for stakeholder management, thereby it means directing scarce resources from shareholders to stakeholders, and it is understood as hurting organization's value. It is apparent that proponents of stakeholder theory do not agree with this and claim that such goal of an organization is too narrow and does not take into account multiple interests of other stakeholders who often have different views, needs, and expected outcomes (McGlone et al. 2011). How should the managers act and make decisions when there are so many different and often divergent interests/claims? Though it is claimed that all of the different corporate constituencies benefit from sustained superior firm performance in the long run (Garcia-Castro et al. 2011; Barnea, Rubin 2010; Jones, Wicks 1999, Foote et al. 2010), but the problem with the long-run view is that it assumes away some potential short-run "frictions" (Prahalad 1997). It often means that short-run pressures and constraints on managers do, in practice, curb some well-intended stakeholder- oriented policies in many firms (Garcia-Castro et al. 2011).

While there is abundant academic literature on stakeholder management (e.g., Habisch et al. 2011; Leea et al. 2013; Horisch et al. 2014; Notteboom et al. 2015; Mok et al. 2015, Meixell, Luoma 2015; Agudo-Valiente et al. 2015), the concept itself is not fully developed concerning its efficient implementation in to practice. The purpose of the paper is to employ fuzzy logic model for conceptual insights on possible solutions for measuring stakeholders' influence and thus enable managers to take decisions. It explores the issues that are important to the stakeholder management and offers empirical insights on organization-stakeholder possible interactions. In our research we treat all stakeholders according to their influence and they all can become important it only depends upon the issue that organization is considering. Consequently it is necessary to identify stakeholders who are related to the issue and to categorize them according to their attributes/factors: power, interest, benevolence, and reliability. The gathered information on stakeholders could explain or predict their influence to the issues the organization seeks to solve and could help to avoid potential "frictions".

The paper is organized as follows: Section 1 provides the overview of stakeholder theory. Section 2 explains stakeholder management from descriptive, instrumental, and normative approach. Consequently the steps of stakeholder analysis are discussed in section 3. The research methodology, application of fuzzy logic technique are analysed in section 4 and final section concludes the study. 


\section{The overview of stakeholder theory}

"Stakeholder theory" or "stakeholder thinking" has emerged as a new narrative to understand and remedy three interconnected business problems: the problem of understanding how value is created and traded, the problem of connecting ethics and capitalism, and the problem of helping managers think about management such that the first two problems are addressed (Parmar et al. 2010). The earliest mentioning of stakeholders can be tracked to 1963 when Stanford Research Institute conceptualized them as "those groups without whose support the organization would cease to exists" (Freeman, Reed 1983). However the most cited definition was proposed by Freeman (1984) which included those groups or individuals who are affected by the organization as well as those who can affect it (Freeman, McVea 2006; Bryson et al. 2002; Ackermann, Eden 2011).

Conceptualizing Freeman's definition it can be noticed that it implies social and ethical aspects, i.e. managers are responsible for society and any member from society has legitimacy concerning organization's actions and decisions. Regarding this and other definitions the stakeholder theory is analyzed from the three approaches: descriptive, instrumental, and normative (ethical considerations). Normative means that there must be certain behaviour standards for managers/organizations. Instrumental theory has utilitarian nature and tests financial effects when organization follows the stakeholder approach. The descriptive usually states the behaviour of organizations/managers, analyzes the classification of stakeholders, organizational decision processes, information disclosure, even attractiveness of stakeholders (Antonacopoulou, Meric 2005).

\section{Stakeholder management}

Over the last decade research on stakeholder management has made enormous progress (Rühli, Sachs 2005; Carroll 1996; Freeman 1994; Post et al. 2002; Waddock, Bodwell 2002; Harrison, Freeman 1999; Feerman, McVea 2006; Phillips 2003). Donaldson and Preston (1995) have already claimed that the management of stakeholder relations is one of its basic challenges. The influence of stakeholders is a central issue in regard to organizational change (Mano 2013).

The aim of stakeholder management is to maximize the benefits that can be derived from stakeholders while minimizing the possible downsides that can arise by associating with them (Landin 2011). Stakeholder management creates a unique and valuable network of stakeholder relations which leads to the acquirement of know-how and competences forming corporate culture and giving rise to benefits for key stakeholders in the long run. A good example for this situation is the well-known claim for customer focus. Interacting with its customers a company gets experience and feedback from them. On the basis of the knowledge and the experience of the company's customers, new and better core competencies can be found. Simultaneously, the employees are stimulated by these interactions and are motivated as they can deal with new ideas and satisfied customers (Rühli, Sachs 2005). Furthermore, the shareholders/investors benefit from this situation as innovative solutions lead to a competitive advantage, and therefore, also to higher success. Consequently it prompts the idea that a proactive stakeholder strategy 
can help the management to minimize costs and to enhance the chances of innovative core competencies based on stakeholder relations.

Relationships between the organization and key stakeholder groups evolve over time and it is important to understand the development of these relationships. Of all the stakeholders in economic processes, enterprise forms the hub of all economic developmentrelated activities (Sanz-Mendiola et al. 2012). The majority of the academic literature seeks to find the suitable foundation for stakeholder management where more often stakeholder management is understood as an issue not only for a particular managers but rather for the whole organization.

Implemented stakeholder management system can provide a tool for answering these questions (Fig. 1).

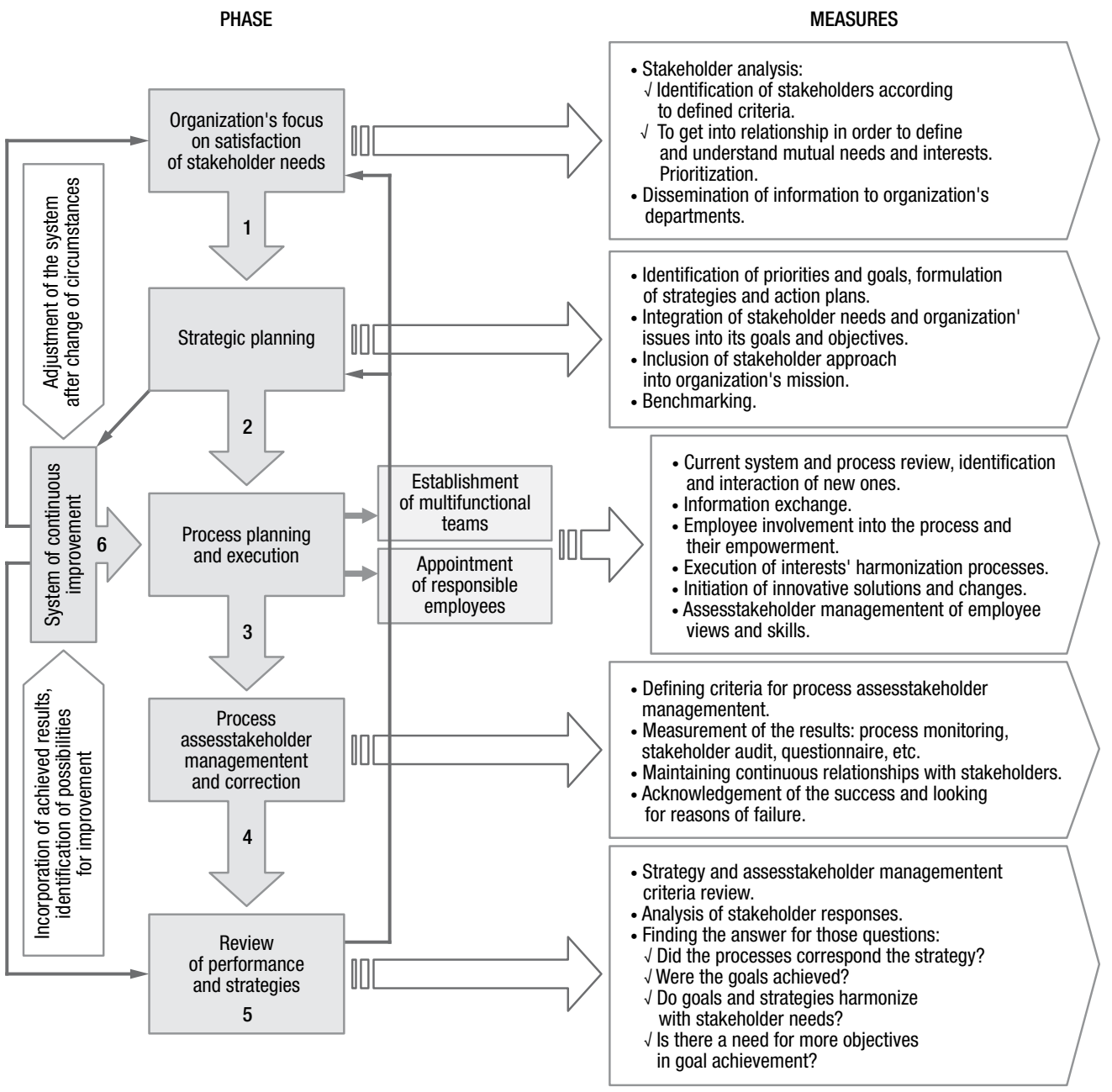

Fig. 1. Stakeholder management system

Source: created by authors. 
Organizations should see their stakeholders as an integral part of their business environment and this part should be managed so as to ensure benefit. From this aspect stakeholder management can be viewed as a part of strategy where important stakeholders are involved. It can be presented as system based on Deming-Shewhart PDCA (plan-do-study-act) cycle and cover planning: design or revision of business process components (phases 1-3), doing: implementation of the plan and measurement of its performance (phases 3-4), studying: assessment of the measurements and report of the results to decision makers (phase 5), and acting: decisions on changes needed to improve the process (phase 6). Stakeholder management system reveals issues that are important to the stakeholder management process, gives better understanding on how the processes work, and how conceptual framework addresses the relevant issues. The model of stakeholder management is not only a descriptive framework but it also leads to recommendations on procedures, tools and implementation processes.

Stakeholder relationships can play a decisive role to smooth the effects of business cycles in the firms by its contribution to the consolidation of the stakeholders' relation (Alajoutsijärvi et al. 2012). Stakeholder management that is adjusted to organizational processes can help the organizations to successfully develop in the turbulent environment. Every organization has the processes that involve different performance aspects. Reflecting stakeholder needs in these processes helps organizations to achieve better results.

\section{Stakeholder analysis}

Stakeholder analysis and engagement are the main tasks in stakeholder management (Yang et al. 2011). The purpose of stakeholder analysis is to indicate whose interests and why should be taken into account when making a decision. So we must ask and answer for ourselves questions such as "Who are the stakeholders?", "How can we gain insight into their interests and values?", "What is total effect when there is more than one dimension of stakeholder attributes" and "How can we simultaneously address what are certain to be conflicting interests and values among the various stakeholder groups?" (Rebentisch et al. 2005).

The competitive stakeholder analysis is a good method for identification of stakeholders, their prioritization and in that way influences the situation and gets the output that creates additional value. The list of stakeholders of a particular organisation can vary over time and is dependent on factors that determine the prevailing power balance among various parties, such as culture, type of market, and government system (Garvare, Johansson 2010). Stakeholder analysis can be executed by identification of them and defining them according to the attributes, interaction and interests in relationship with the dealt issue.

The benefit from stakeholder manifests in different forms: a stakeholder can bring new resources, provide know-how, help with entering new markets or otherwise increase the organization's strength. Second, it depends on stakeholder attitude to the issue, i.e. if it is negative and threatening or it can weaken company's position/support or even bring 
damage, then it should be given a close consideration. One more stakeholder aspect influence - must also be considered. The influence should be considered as a wider concept which covers several stakeholder attributes (e.g. power, interest, benevolence, reliability) and their presence and strength can determine degree of a positive/negative influence.

\section{The research}

It is impossible for all stakeholders to have the same interests and needs. Once organizations have identified their stakeholders, it is necessary to define the importance of satisfaction of their needs to organization i.e., which stakeholder needs should be satisfied and which needs should be postponed for future (this depends upon situation and such stakeholder attributes as power and interest). There will always be a stakeholder week or even to some extent unfavourable for the organization needs that could be left unsatisfied for some time and negative influence avoided. Therefore the problem of prioritization and evaluation of the total influence arises and encompasses different factors.

The research takes into account one more dimension of stakeholder attributes that is missing in Mitchell et al. (1997) and this is whether the stakeholder group is supportive (benevolent) or not. Any stakeholder or their group could be supportive or threatening, and stakeholder strategies would be contingent on the level of support. This means that a comprehensive and quantitative model of stakeholder influence evaluation and prioritization should also identify whether stakeholders are supportive or threatening and how much.

While numerous schemes have been created that identify, categorize, and prioritize corporate stakeholders (Clarkson 1995; Campbell, Alexander 1997; Freeman 1984; Goodpaster 1991; Phillips 2001; Mitchell et al. 1997; Grunig 2005) in this research we do not focus on steps how to identify stakeholders we rather go further to the next step and consider their influence according to such attributes as interest, power, benevolence (position on the issue, supportive or not), and reliability (how trustworthy a stakeholder is when certain agreements are achieved). Reliability factor is more or less a personal stakeholder's trait or it can be determined by the situation, but we consider it as an important attribute/factor influencing stakeholder's behaviour as a stakeholder or his/her intentions can be very benevolent but for some reasons he/she is not taking any agreed actions concerning the issue. Legal or ethical factor "legitimacy" and time sensitive factor "urgency" should be taken into account after the level of stakeholder influence has been identified. The evaluation of the attributes (power, interest, benevolence and reliability) and their all possible interactions would enable the management to clarify for themselves what actions to take when dealing with the stakeholders or their groups, which stakeholder or group should be given a priority or which stakeholder or group could be involved to support the decisions. For example a stakeholder has power, benevolence but no interest. If there is a need to strengthen the position in tackling the problem the organization can take certain actions to interest and involve that stakeholder. Another example can be given about reliability. At first sight it can be assumed if it is low then it can bring negative effect. But this is not always true because if interest 
is high or medium, low reliability can be expected not to manifest in case benevolence is positive. The combination of these four attributes/factors and their strength can bring different outcomes to organization.

Therefore with our research we try to point to the need of gathering different information about stakeholder, to consider what is known and not known about various stakeholders having in mind the discussed four attributes above.

This research offers a quantitative computer model of gathered or available qualitative information about stakeholders. The model is based on fuzzy logic of these four attributes/factors and their influence as a practical tool for dealing with the stakeholder management issues and can be used in management for making decisions.

\section{The research methodology}

Modelling and computer simulation can contribute to a deeper understanding of the issue (Scheffran 2006). To develop a model that enables to explain or predict what could happen if some parameters are changed usually one needs precise estimation of these parameters, input and output variables.

Unfortunately, the knowledge and verbal conclusions of experts about the influence of input factors or parameters on output (in our case on organization's performance) cannot be considered as precise. They are approximate and contain uncertainty from the mathematical viewpoint.

To overcome these differences between qualitative and precise quantitative models and to build a digital model based on qualitative knowledge and estimation of influence on the organization in a form of fuzzy logic was suggested to apply. Fuzzy logic is a precise logic of imprecision and approximate reasoning (Zadeh 2008).

The fuzzy sets and fuzzy logic were introduced by prof. Lofti A. Zadeh in his research papers (Zadeh 1965, 1989). Over the years since these ideas were published, his proposal has gained recognition in various fields of the research (Celikyilmaz, Türksen 2009).

This research was an attempt to apply fuzzy logic ideas to develop a model of the input factors/attributes (benevolence, interest, power and reliability) and their influence on the enterprise.

In order to give quantitative evaluation of these factor, each factor was divided into three linguistic levels, called terms in fuzzy logic, - interest and power into levels low, medium and high, benevolence into negative, neutral, positive and influence into negative, zero and positive. These levels enabled to code expert-type knowledge into IF THEN rules, for instance:

IF benevolence is negative,

and interest is medium,

and power is high,

and reliability is low,

THEN influence is negative. 
Taking into account that the IF part, called antecedent of the rules, was comprised of four factors benevolence, interest, power and reliability where each had three levels, then the rule base consisted of $3^{4}=81$ rules.

The problem of knowledge uncertainty can be conveyed and discussed in details following the case of factor interest. The factor was split into three linguistic levels - low, medium and high and besides that, the factor was assigned scores $x$ ranging from 0 (lowest) to 10 (highest). This implied that scores were also divided into three subsets corresponding to above mentioned levels - low, medium and high. In traditional set theory, there exists a clear distinction between members and non-members of a set. Contrary to crisp sets, a fuzzy set or subsets, as in our case, can partially overlay each other and thus can be formed by assigning a membership value $m_{\text {level }}(x)$ to each level in the interval of [0,1] (Celikyilmaz, Türksen 2009). If, for instance, interest was evaluated with score $x=7$ and was calculated $m_{\text {high }}(7)=0.6$, then this means that such interest belongs to the level high with membership value 0.6 . It should be understood that the assertion " $x$ is high" is true just with degree 0.6 , while the absolute truth has degree 1 . The statement that is absolute false has the degree of truth equal 0 , for instance, the statement " $x=7$ is low" is absolutely false, hence $m_{\text {low }}(7)=0$.

Figure 2 shows that membership functions overlap. For instance, when the score $x=4$, then such interest is medium with the truth $m_{\text {medium }}(4)=0.7$ and is low with the truth $m_{\text {low }}(4)=0.3$ (Fig. 2). Hence, if the evaluation $x$ of the factor interest slightly changes or two experts give close to 4 but different scores, then anyway the interest evaluation as partially low ant partially medium remains right, just slightly change the degree of truth of both evaluations. This enables to overcome the problem of imprecision of qualitative knowledge.

Similarly for input factor benevolence three membership functions $m_{\text {negative }}(x), m_{\text {neutral }}(x)$ and $m_{\text {positive }}(x)$ were constructed. The factor was assigned scores $x$ ranging from -10 (lowest) to 10 (highest). Scores with negative sign indicated the negative influence direction of the stakeholder on the organization. For the input factors power, reliability and the output factor influence membership functions $m_{\text {low }}(x), m_{\text {medium }}(x)$ and $m_{\text {high }}(x)$

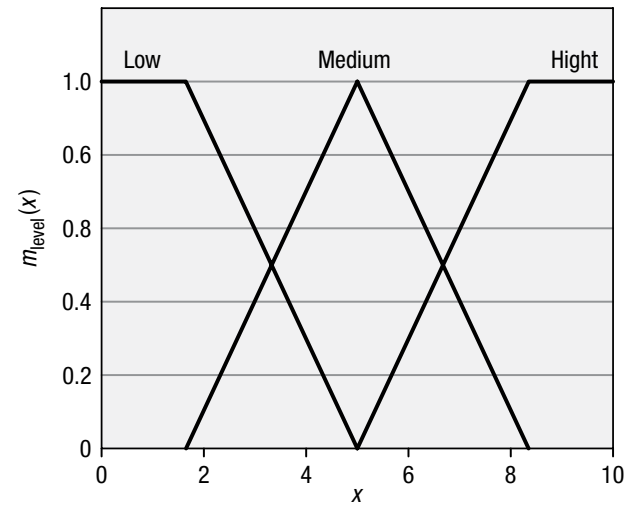

Fig. 2. Membership functions $m_{\text {low }}(x), m_{\text {medium }}(x)$ and $m_{\text {high }}(x)$ of the factor interest 
were also constructed. The factor power was assigned scores $x$ ranging from 0 (lowest) to 10 (highest) like the factor interest. The factor reliability was assigned scores $x$ ranging from 0 (lowest) to 5 (highest). This different from another factors' range was chosen to demonstrate that the range is not necessary to be from interval $[0,10]$. For instance, the range $[0,10]$ can be obtained from range $[0,5]$ by multiplying scores with 2. Neighbouring membership functions were overlapped. This assured compatibility of imprecise qualitative knowledge.

Thus the general structure of the fuzzy inference system took the form as shown in Figure 3. There the input factors are shown on the left side. Values of these factors are processed by the rules block and performed by fuzzy interface. And finally, the digital value of the influence is obtained by the defuzzification.

The relationship between input and output is called inference system. The system was based on expert qualitative knowledge given in the Table 1. It is seen from the table that expert was asked to evaluate just linguistically possible influences ofstakeholders influnce on the concrete enterprise under variuos possible combinations of power, interest, reliability and benevolence. The inference engine consist of IF...THEN rules derived from expert knowledge and it is a sophisticated rule base as the each input

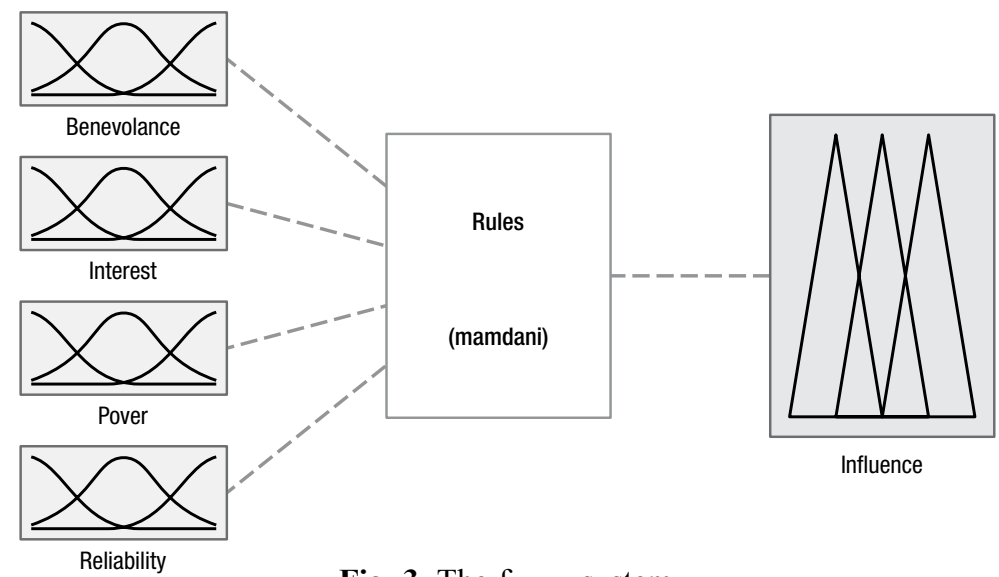

Fig. 3. The fuzzy system

Source: created by authors.

Table 1. Qualitative knowledge about stakeholdersinflunce on the enterprise " $\mathrm{H}$ " under variuos combinations of power, interest, reliability and benevolence

\begin{tabular}{ccccc}
\hline $\begin{array}{c}\text { POWER: } \\
\begin{array}{c}\text { low, medium, } \\
\text { high }\end{array}\end{array}$ & $\begin{array}{c}\text { INTEREST: } \\
\text { low, medium, } \\
\text { high }\end{array}$ & $\begin{array}{c}\text { RELIABILITY: } \\
\text { low, medium, } \\
\text { high }\end{array}$ & $\begin{array}{c}\text { BENEVOLENCE: } \\
\text { negative, neutral, } \\
\text { positive }\end{array}$ & $\begin{array}{c}\text { INFLUENCE: } \\
\text { positive, zero, } \\
\text { negative }\end{array}$ \\
\hline low & low & low & negative & \\
\hline low & low & low & neutral & \\
\hline$\ldots$ & & & & \\
\hline high & high & high & positive & \\
\hline
\end{tabular}


factor may simultaneously partially belong to two fuzzy levels. This implies that four input factors may simultaneously activate up to $2^{4}$ rules with different contribution to the output factor influence.

Several methods exist to compute the output variable values (Celikyilmaz, Türksen 2009). This research was based on the convenient Mamdani inference method as it suited well for the types of membership functions used for factor influence fuzzy levels. The developed model enables to explore the connection between input and output factors and to visualize this dependence in 3D space (Fig. 4). For instance, in given figure there is plotted an influence dependence on interest and power, while other two factors are fixed at their levels benevolence $=$ neutral and reliability $=4.5$ (partially neutral, partially low). This demonstrates that modelling by fuzzy logic factors can be assigned concrete scores or verbal levels as well. It is seen that at this fixed levels of benevolence and reliability the maximal influence is about 6 score points and it is reached when interest is high about 9-10 scores and does not depend on power. But it is the case when power is high. For all power values the influence remains dependent on interest and the influence increases along with interest increase. The plot also reveals that interest and power interact resulting in maximal values of the influence.

Similarly the model enables to present and to analyse the dependence of the influence on any two factors when the remaining another two factors are fixed at the arbitrary level. It should be pointed out that the fuzzy rule base was just verbal mapping of expert-type knowledge and at no stage of the model development there were no explicit quantitative dependence of the output factor influence on the formulated input factors benevolence, interest, power and reliability. Nevertheless the model, as it is seen in the Figure 3, is quantitative and can be used in more general mathematical models.

Many fuzzy logic modelling environments, for instance such as Matlab Fuzzy add-on or FuzzyTech, have a capability to export model into programming language stand-alone code. This code can be later used in another more general model. For instance in agentbased models the fuzzy submodel code may be used by intellectual agents, say suppliers or firms, in decision making or for evaluation of the dynamic business environment.

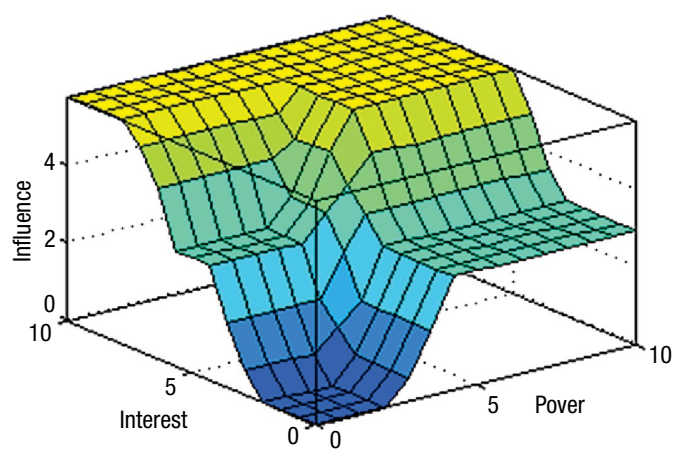

Fig. 4. Plot of the influence dependence on interest and power when other factors are fixed: benevolence $=$ neutral and reliability $=4.5$ (partially neutral, partially low) 
The analysis of dependence plot also enables to find possible errors or contradictions in expert knowledge given in the rule form. If three input parameters are fixed and one is left to change, say interest, then the corresponding dependence influence (interest) should form a monotonous (increasing in this case) curve on the surface. If not, i.e. the surface has a local minimum or maximum, then there should be an inconsistence in the rule base.

To test the feasibility of the model against the expert knowledge, i. e. against the source data, the numerical defuzzified evaluation at different points was computed and compared with expert knowledge, corresponding to maximum values of membership functions (Fig. 1). The comparison is given in the Table 2. It is seen from the table that predicted by the fuzzy model influence numerical evaluation does not contradict expert verbal evaluation. But on the other hand the model avoids giving maximal evaluation of the possible influence. That can be explained by the fuzziness of the method and expert knowledge as well.

Table 2. Comparison the fuzzy model predicted influence against expert evaluation

\begin{tabular}{cccccc}
\hline Power, & Interest, & Reliability, & Benevolence, & \multicolumn{2}{c}{ Influence $y$} \\
$(x)=1$ & $\mathrm{mb}(x)=1$ & $\mathrm{mb}(x)=1$ & $\mathrm{mb}(x)=1$ & expert & $\begin{array}{c}\text { fuzzy model, } \\
\text { predicted } y\end{array}$ \\
\hline low, $x=1.5$ & low, $x=1.5$ & low, $x=0.5$ & $\begin{array}{c}\text { negative, } \\
x=-8\end{array}$ & $\begin{array}{c}\text { neutral, } \\
-5<y<5\end{array}$ & $y=-0.05$ \\
\hline high, $x=9$ & low, $x=1.5$ & low, $x=0,5$ & $\begin{array}{c}\text { negative, } \\
x=-8\end{array}$ & $\begin{array}{c}\text { negative, } \\
-10<y<-5\end{array}$ & $y=-6.16$ \\
\hline low, $x=1.5$ & high, $x=9$ & low, $x=0.5$ & $\begin{array}{c}\text { negative, } \\
x=-8\end{array}$ & $\begin{array}{c}\text { negative, } \\
-10<y<-5\end{array}$ & $y=-6.16$ \\
\hline high, $x=9$ & high, $x=9$ & low, $x=0.5$ & positive, $x=8$ & $\begin{array}{c}\text { positive, } \\
5<y<10\end{array}$ & $y=6.18$ \\
\hline high, $x=9$ & high, $x=9$ & high, $x=4.5$ & positive, $x=8$ & $\begin{array}{c}\text { positive, } \\
5<y<10\end{array}$ & $y=7.10$ \\
\hline
\end{tabular}

Besides this, a concrete other similar enterprise " $\mathrm{N}$ " that supplies a definite service to hospitals and other medical institutions was chosen. An expert was asked to evaluate the power, interest, benevolence, reliability of two given stakeholders and to evaluate their influence on the enterprise. The evaluations of expert were compared with evaluation given by the developed fuzzy model system (Table 3).

Referring to Table 3 data it can be noticed that the model system in both cases gave somewhat lower evaluation in scores but the same evaluation in linguistic terms. The systematically slightly lower evaluation given by the system may be explained, that the fuzzy model was developed with very general assumptions and knowledge about one enterprise while the test was carried out on real data of another enterprise. Taking into account that the linguistic evaluations of the experts and the model in both tests do not contradict, the performance of the fuzzy system should be assumed as reliable. 
Table 3. Comparison of expert and fuzzy system‘s evaluations

\begin{tabular}{cccccccc}
\hline & & & & & \multicolumn{2}{c}{$\begin{array}{c}\text { Influence values }-10 \text { to } 10 \\
\text { and linguistic levels }\end{array}$} \\
\cline { 6 - 8 } Stakeholder & $\begin{array}{c}\text { Power } \\
0-10\end{array}$ & $0-10$ & $-10-10$ & $0-5$ & $\begin{array}{c}\text { According } \\
\text { to expert }\end{array}$ & $\begin{array}{c}\text { According } \\
\text { to model }\end{array}$ \\
\hline Hospital "H" & 6 & 10 & 9 & 4.5 & 7, positive & 6, positive \\
\hline Newspaper "P" & 5 & 0 & 1 & 1 & 3, zero-positive & 1 , zero-positive \\
\hline
\end{tabular}

\section{General commentary and conclusions}

The research was built on the works of other researchers who have generated new ideas and techniques in exploration of stakeholder management and analysis as the development of positive relationships with stakeholders is a necessity for organizations. Therefore the organization with its management must be proactive in gathering information about stakeholder positions, needs and interests as to plan future steps in taking certain actions or making decisions and avoiding negative influence from them. For this purpose it was necessary to identify stakeholder attributes (interest, power, benevolence, and reliability) that are important in deciding about their influence, and to take into account all possible attribute interactions that could reflect stakeholder influence and its strength to organization and to offer possible solutions in strive of interest harmonization between organization and its stakeholders.

The research made its contribution by offering a theoretical framework for a stakeholder management system. From a practical point of view, our results provide some guidelines for the management and the boards when dealing with various stakeholders regarding their various attributes and effectively monitoring management policy.

Another contribution of this paper is the application of fuzzy logic model in explaining and/or predicting stakeholders' influence to the issues the organization seeks to solve and to provide relevant information for the stakeholder relationships management. The fuzzy modelling enabled to develop the quantitative dependence of the factor influence on the factors benevolence, interest, power and reliability from qualitative knowledge containing in the linguistic rule base. The fuzzy model's 3D plots depict the qualitative knowledge graphically and make it easy to analyse and to evaluate the resulting influence of the discussed above factors and their interactions. Besides this, the fuzzy model developing process enables to notice possible inconsistencies in the qualitative knowledge. The stand-alone code of the entire fuzzy model may be used in more general agent-based models as a decision making engine of intellectual agents.

Concerning the model the intention was to present conceptual insights on possible solutions of measuring stakeholders' influence. Therefore no solutions for all possible enterprises and stakeholders were included. The concrete adjustments to the model should be made for concrete enterprise.

To summarize, the key idea of the article is that, on that basis of stakeholder management literature and the authors' ideas, managers should be offered some practical tool 
to efficiently deal with the stakeholder management issues as right decisions in the short run perspective generate beneficial outcomes for long run perspective. And there is an obvious need to continue the research and carry out an elaborate empirical testing of the discussed digital model (based on qualitative estimation of influence on the organization) on the organizations and suggest useful further insights in modelling technique and in application and operation of stakeholder management relationships for successful decision making and cooperation with them.

\section{References}

Ackermann, F.; Eden, C. 2011. Strategic management of stakeholders: theory and practice, Long Range Planning 44(3): 179-196. http://dx.doi.org/10.1016/j.lrp.2010.08.001

Agudo-Valiente, J. M.; Garces-Ayerbe, C.; Salvador-Figueras, M. 2015. Corporate social performance and stakeholder dialogue management, Corporate Social Responsibility and Environmental Management 22(1): 13-31. http://dx.doi.org/10.1002/csr.1324

Antonacopoulou, E. P.; Meric, J. 2005. A critique of stake-holder theory: management science or a sophisticated ideology of control?, Corporate Governance 5(2): 22-33. Emerald Group Publishing Limited. ISSN 1472-0701. http://dx.doi.org/10.1108/14720700510562631

Alajoutsijärvi, K.; Mainela, T.; Ulkuniemi, P.; Montell, E. 2012. Dynamic effects of business cycles on business relationships, Management Decision 50(2): 291-304.

http://dx.doi.org/10.1108/00251741211203579

Barnea, A.; Rubin, A. 2010. Corporate social responsibility as a conflict between shareholders, Journal of Business Ethics 97(1): 71-86. http://dx.doi.org/10.1007/s10551-010-0496-Z

Benson, B. W.; Davidson III, W. N.; Wang, H.; Worrell, D. L. 2011. Deviations from expected stakeholder management, firm value, and corporate governance, Financial Management 40(1): 39-81. http://dx.doi.org/10.1111/j.1755-053X.2010.01134.x

Bhattacharya, C.; Korschun, D.; Sen, S. 2009. Strengthening stakeholder-company relationships through mutually beneficial corporate social responsibility initiatives, Journal of Business Ethics 85: 257-272. http://dx.doi.org/10.1007/s10551-008-9730-3

Bryson, J. M.; Cunningham, G. L.; Lokkesmoe, K. J. 2002. What to do when stakeholders matter: the case of problem formulation for the African American men project of Hennepin county, Minnesota, Public Administration Review 62(5): 568-584. http://dx.doi.org/10.1111/1540-6210.00238 Campbell, A.; Alexander, M. 1997. What's wrong with strategy?, Harvard Business Review November-December: 42-51.

Carroll, A. B. 1996. Business and society - ethics and stakeholder management. 3rd ed. Cinncinati, OH: South-Western Publishing Co.

Celikyilmaz, A.; Türksen, I. B. 2009. Modeling uncertainty with fuzzy logic. Berlin Heidelberg: Springer-Verlag. http://dx.doi.org/10.1007/978-3-540-89924-2_5

Clarkson, M. B. E. 1995. A stakeholder framework for analyzing and evaluating corporate social performance, Academy of Management Review 20(1): 92-117.

http://dx.doi.org/10.5465/AMR.1995.9503271994

Donaldson, T.; Preston, L. E. 1995. The stakeholder theory of the corporation: concepts, evidence, and implications, Academy of Management Review 20(1): 65-91.

http://dx.doi.org/10.5465/AMR.1995.9503271992

Duijvesteijn, N.; Benard, M.; Reimert, I.; Camerlink, I. 2014. Same pig, different conclusions: stakeholders differ in qualitative behaviour assessment, Journal of Agricultural \& Environmental Ethics 27(6): 1019-1047. http://dx.doi.org/10.1007/s10806-014-9513-z 
Foote, J.; Gaffney, N.; Evans, J. R. 2010. Corporate social responsibility: implications for performance excellence, Total Quality Management \& Business Excellence 21(8): 799-812. http://dx.doi.org/10.1080/14783363.2010.487660

Freeman, E. 1994. The politics of stakeholder theory: some future directions, Business Ethics Quarterly 4(4): 409-22. http://dx.doi.org/10.2307/3857340

Freeman, R. E. 1984. Strategic management: a stakeholder approach. Boston: Pitman Publishing. Freeman, R. E.; Reed, D. L. 1983. Stockholders and stakeholders: a new perspective on corporate governance, California Management Review 25(3): 88-106. http://dx.doi.org/10.2307/41165018

Freeman, R. E.; McVea, J. 2006. A stakeholder approach to strategic management, in M. Hitt, E. Freeman, J. Harrison (Eds.). Handbook of strategic management. Oxford: Blackwell Publishing, 189-207. http://dx.doi.org/10.1111/b.9780631218616.2006.x

Fung, M. K. 2009. Is innovativeness a link between pay and performance?, Financial Management 38(2): 411-429. http://dx.doi.org/10.1111/j.1755-053X.2009.01041.x

Garcia-Castro, R.; Ariño, M. A.; Canela, M. A. 2011. Over the long-run? Short-run impact and long-run consequences of stakeholder management, Business and Society 50(3): 428-455.

http://dx.doi.org/10.1177/0007650308315493

Garvare, R.; Johansson, P. 2010. Management for sustainability - a stakeholder theory, Total Quality Management \& Business Excellence 21(7): 737-744.

http://dx.doi.org/10.1080/14783363.2010.483095

Goodpaster, K. 1991. Business ethics and stakeholder analysis, Business Ethics Quarterly 1(1): 53-73. http://dx.doi.org/10.2307/3857592

Grunig, J. E. 2005. Situational theory of publics, Encyclopedia of Public Relations. Thousand Oaks, CA: Sage, 778-780. http://dx.doi.org/10.4135/9781412952545

Habisch, A.; Patelli, L.; Pedrini, M.; Schwartz, C. 2011. Erratum to: different talks with different folks: a comparative survey of stakeholder dialog in Germany, Italy, and the U.S., Journal of Business Ethics 100:381-404. http://dx.doi.org/10.1007/s10551-010-0686-8

Harrison, J. S.; Freeman, R. E. 1999. Stakeholders social responsibility and performance: empirical evidence and theoretical perspectives, Academy of Management Journal 42(5): 479-485. http://dx.doi.org/10.2307/256971

Horisch, J.; Freeman, R. E.; Schaltegger, S. 2014. Applying stakeholder theory in sustainability management: links, similarities, dissimilarities, and a conceptual framework, Organization \& Environment 27(4): 328-346. http://dx.doi.org/10.1177/1086026614535786

Jones, T. M.; Wicks, A. C. 1999. Convergent stakeholder theory, Academy of Management Review 24(2): 206-221. http://dx.doi.org/10.5465/AMR.1999.1893929

http://dx.doi.org/10.3846/16111699.2011.620151

Landin, A. 2011. Construction stakeholder management, Construction Management and Economics 29(1): 107-107. http://dx.doi.org/10.1080/01446193.2010.529923

Leea, C.-K.; Songb, H.-J.; Leea H.-M.; Leec, S.; Bernhardd, B. J. 2013. The impact of CSR on casino employees' organizational trust, job satisfaction, and customer orientation: an empirical examination of responsible gambling strategies, International Journal of Hospitality Management 33: 406-415. http://dx.doi.org/10.1016/j.ijhm.2012.10.011

Mano, R. 2013. Performance gaps and change in Israeli nonprofit services: a stakeholder approach, Administration in Social Work 37(1): 14-24.

http://dx.doi.org/10.1080/03643107.2011.637664

McGlone, T.; Spain, J. W.; McGlone, V. 2011. Corporate social responsibility and the millennials, Journal of Education for Business 86(4): 195-200.

http://dx.doi.org/10.1080/08832323.2010.502912 
Meixell, M. J.; Luoma, P. 2015.Stakeholder pressure in sustainable supply chain management A systematic review. International Journal of Physical Distribution \& Logistics Management 45(1-2): 69-89. http://dx.doi.org/10.1108/IJPDLM-05-2013-0155

Metaxas, T.; Tsavdaridou, M. 2010. Corporate social responsibility in Europe: Denmark, Hungary and Greece, Journal of Contemporary European Studies 18(1): 25-46.

http://dx.doi.org/10.1080/14782801003638679

Mitchell, R. K.; Agle, B. R.; Wood, D. J. 1997. Toward a theory of stakeholder identification and salience: defining the principle of who and what really counts, Academy of Management Review 22(4): 853-886. http://dx.doi.org/10.2307/259247

Mok, K.Y.; Shen, G.Q.; Yang, J. 2015. Stakeholder management studies in mega construction projects: a review and future directions, International Journal of Project Management 33(2): 446-457. http://dx.doi.org/10.1016/j.ijproman.2014.08.007

Notteboom, T.; Parola, F.; Satta, G.; Penco, L. 2015. Disclosure as a tool in stakeholder relations management: alongitudinal study on the Port of Rotterdam, International Journal of LogisticsResearch and Applications 18(3): 228-250. http://dx.doi.org/10.1080/13675567.2015.1027149

Parmar, B. L.; Freeman, R. E.; Harrison, J. S.; Wicks, A. C.; Purnell, L.; Colle, S. 2010. Stakeholder theory: the state of the art, The Academy of Management Annals 4(1): 403-445.

http://dx.doi.org/10.1080/19416520.2010.495581

Phillips, R. 2003. Stakeholder theory and organizational ethics. San Francisco, CA: BerrettKoehler.

Phillips, R. 2001. Stakeholder legitimacy: a preliminary investigation. Working paper. Georgetown University Business School, Washington, DC.

Post, J. E.; Preston, L. E.; Sachs, S. 2002. Managing the extended enterprise: the new stakeholder view, California Management Review 45(1): 6-28. http://dx.doi.org/10.2307/41166151

Prahalad, C. K. 1997. Corporate governance or corporate value added? Rethinking the primacy of shareholder value, in D. Chew (Ed.). Studies in international corporate finance and governance systems. New York: Oxford University Press, 46-56.

Rebentisch, E. S.; Crawley, E. F; Loureiro, G.; Dickmann, J. Q.; Catanzaro, S. N. 2005. Using stakeholder value analysis to build exploration sustainability, in Proceedings of the AIAA 1st Space Exploration Conference: Continuing the Voyage of Discovery, 30-31 January 005, Orlando, Florida.

Rühli, E.; Sachs, S. 2005. Practical issues in implementing the stakeholder view as a core competence, in R. Sanchez, A. Heene (Eds.). Perspectives on resources, stakeholders, and renewal, Advances in Applied Business Strategy 9: 217-233.

http://dx.doi.org/10.1016/S0749-6826(05)09011-6

Sanz-Mendiola, I.; Garcia-Beltran, A.; Tirados, R. M. G. 2012. Evaluation and implementation of social responsibility, The Service Industries Journal 33(9-10): 846-858.

http://dx.doi.org/10.1080/02642069.2013.719890

Scheffran, J. 2006. Tools for stakeholder assesstakeholder managementent and interaction, in S. Stoll-Kleemann, M. Welp (Eds.). Stakeholder dialogues in natural resources management: theory and practice. Berlin: Springer, 153-186. http://dx.doi.org/10.1007/978-3-540-36917-2_6

Singer, A. 2013. Teaching ethics cases: a pragmatic approach, Business Ethics: a European Review 22(1): 16-31. http://dx.doi.org/10.1111/beer.12004

Sprinkle, G. B.; Maines, L. A. 2010. The benefits and costs of corporate social responsibility, Business Horizons 53(5): 445-453. http://dx.doi.org/10.1016/j.bushor.2010.05.006

Waddock, S.; Bodwell, C. 2002. From TQM to TRM: total responsibility management approaches, Journal of Corporate Citizenship 7: 113-126. 
West, R.; Turner, L. 2007. Introducing communication theory. McGraw Hill.

Yang, J.; Shen, G. Q.; Bourne, L.; Ho, C. M-F; Xue, X. 2011. A typology of operational approaches for stakeholder analysis and engagement, Construction Management and Economics 29(2): 145-162. http://dx.doi.org/10.1080/01446193.2010.521759

Zadeh, L. A. 1965. Fuzzy sets, Information and Control 8: 338-353.

http://dx.doi.org/10.1016/S0019-9958(65)90241-X

Zadeh, L. A. 1989. Knowledge representation in fuzzy logic, IEEE Transactions on Knowledge and Data Engineering 1(1): 89-100. http://dx.doi.org/10.1109/69.43406

Zadeh, L. A. 008. Is there a need for fuzzy logic?, Information Sciences 178(13): 2751-2779. http://dx.doi.org/10.1016/j.ins.2008.02.012

Dalia SUSNIENĖ is an Associate Professor, Doctor of Social Sciences (Management and administration) in the Faculty of Management and Administration at Kaunas University of Technology. Her research interests are sustainable development, corporate social responsibility, stakeholder management, quality management.

Ojaras PURVINIS is an Associate Professor, Doctor of Mathematics in the Faculty of Technology at Kaunas University of Technology. His research interests are intellectual methods of informatics, mathematical modelling of economics and business processes. 